\title{
Andrographolide Stimulates Neurogenesis in the Adult Hippocampus
}

\author{
Lorena Varela-Nallar, ${ }^{1}$ Sebastian B. Arredondo, ${ }^{1}$ Cheril Tapia-Rojas, ${ }^{2}$ \\ Juan Hancke, ${ }^{3}$ and Nibaldo C. Inestrosa ${ }^{2,4,5}$ \\ ${ }^{1}$ Centro de Investigaciones Biomédicas (CIB), Facultad de Ciencias Biológicas y Facultad de Medicina, Universidad Andrés Bello, \\ Santiago, Chile \\ ${ }^{2}$ Centro de Envejecimiento y Regeneración (CARE), Departamento de Biología Celular y Molecular, Facultad de Ciencias Biológicas, \\ Pontificia Universidad Católica de Chile, Santiago, Chile \\ ${ }^{3}$ Instituto de Farmacología y Morfofisiología, Universidad Austral de Chile, Valdivia, Chile \\ ${ }^{4}$ Center for Healthy Brain Ageing, School of Psychiatry, Faculty of Medicine, University of New South Wales, Sydney, Australia \\ ${ }^{5}$ Centro de Excelencia en Biomedicina de Magallanes (CEBIMA), Universidad de Magallanes, Punta Arenas, Chile
}

Correspondence should be addressed to Lorena Varela-Nallar; lorena.varela@unab.cl and Nibaldo C. Inestrosa; ninestrosa@bio.puc.cl

Received 23 July 2015; Accepted 17 September 2015

Academic Editor: Mauro G. Carta

Copyright (C) 2015 Lorena Varela-Nallar et al. This is an open access article distributed under the Creative Commons Attribution License, which permits unrestricted use, distribution, and reproduction in any medium, provided the original work is properly cited.

\begin{abstract}
Andrographolide (ANDRO) is a labdane diterpenoid component of Andrographis paniculata widely used for its anti-inflammatory

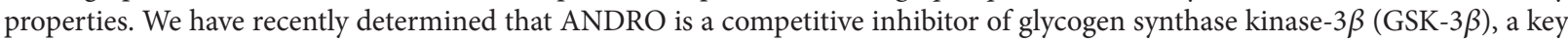
enzyme of the Wnt/ $\beta$-catenin signaling cascade. Since this signaling pathway regulates neurogenesis in the adult hippocampus, we evaluated whether ANDRO stimulates this process. Treatment with ANDRO increased neural progenitor cell proliferation and the number of immature neurons in the hippocampus of 2- and 10-month-old mice compared to age-matched control mice. Moreover, ANDRO stimulated neurogenesis increasing the number of newborn dentate granule neurons. Also, the effect of ANDRO was evaluated in the APPswe/PS1 $\triangle E$ 9 transgenic mouse model of Alzheimer's disease. In these mice, ANDRO increased cell proliferation and the density of immature neurons in the dentate gyrus. Concomitantly with the increase in neurogenesis, ANDRO induced the activation of the Wnt signaling pathway in the hippocampus of wild-type and APPswe/PS1 $\triangle \mathrm{E} 9$ mice determined by increased levels of $\beta$-catenin, the inactive form of GSK-3 $\beta$, and NeuroD1, a Wnt target gene involved in neurogenesis. Our findings indicate that ANDRO stimulates neurogenesis in the adult hippocampus suggesting that this drug could be used as a therapy in diseases in which neurogenesis is affected.
\end{abstract}

\section{Introduction}

Andrographolide (ANDRO) is a labdane diterpenoid that is one of the main constituents of Andrographis paniculata [1,2], a well-known medicinal plant widely used in Asia. ANDRO possesses a wide range of biological activities including antiinflammatory action [3-5] and has also shown neuroprotective properties $[6,7]$. More recently, it was also determined that ANDRO prevents neuropathological changes and improves spatial memory in the APPswe/PS1 $\triangle \mathrm{E} 9$ mouse model of Alzheimer's disease (AD) [8].
Regarding the mechanism of action of ANDRO, we recently determined that it directly inhibits the enzyme glycogen synthase kinase-3 $\beta$ (GSK-3 $\beta$ ) [9], a key enzyme of the Wnt $/ \beta$-catenin signaling pathway. The Wnt signaling pathway is activated by the binding of a Wnt ligand to seven-pass transmembrane receptors Frizzled, which may activate the canonical $\mathrm{Wnt} / \beta$-catenin signaling pathway or noncanonical $\beta$-catenin-independent signaling cascades [10]. The Wnt signaling cascade regulates the development of the nervous system but also is an important modulator of adult nervous system regulating the formation of synaptic contacts, 
neurotransmission, and plasticity [11-13]. In addition, it has been more recently demonstrated that the Wnt signaling pathway regulates the formation of new neurons in the adult hippocampus (reviewed in [14]), a process known as adult neurogenesis.

Adult neurogenesis occurs mainly in two brain regions, the subventricular zone in the wall of the lateral ventricles and the subgranular zone (SGZ) in the hippocampal dentate gyrus $[15,16]$. In the SGZ, neural progenitor cells located between the granule cell layer (GCL) and the hilus proliferate and give rise to neuroblasts that mature into granule cells that integrate into the hippocampal circuitry. These newborn neurons are relevant for hippocampal plasticity, learning, and memory [17-19]. Neurogenesis in the SGZ is controlled by the $\mathrm{Wnt} / \beta$-catenin signaling pathway, which regulates proliferation, differentiation, and maturation of newborn neurons [20-23], effects mediated by the expression of Wnt target genes $[24,25]$. Considering that ANDRO activates the Wnt signaling pathway and the transcription of Wnt target genes [9], in the present study we investigated the effect of ANDRO treatment on neurogenesis in the adult hippocampus. We determined that ANDRO increased cell proliferation and the generation of newborn mature granule cells in young and aged wild-type mice. In addition, ANDRO increased the proliferation and the density of immature neurons in APPswe/PS1 $\triangle \mathrm{E} 9$ mice. In both, wild-type and APPswe/PS1 $\triangle \mathrm{E} 9$ mice, ANDRO increased the activation of the Wnt signaling pathway in the hippocampus and increased the expression of the proneural Wnt target gene NeuroD1.

\section{Materials and Methods}

2.1. Animals and Treatment. Two- and ten-month-old wildtype C57BL/6 mice were injected intraperitoneally (i.p.) with $0.2 \%$ DMSO in saline solution (vehicle) alone or vehicle with $2 \mathrm{mg} \mathrm{kg}^{-1}$ ANDRO (Sigma-Aldrich) 3 times a week for 2, 4 , or 6 weeks. Seven-month-old APPswe/PSEN1 $\triangle$ E9 (stock \#004462, The Jackson Laboratory) were injected i.p. with $2 \mathrm{mg} \mathrm{kg}^{-1}$ ANDRO or vehicle 3 times a week for 4 weeks. 5Bromo-2' -deoxyuridine (BrdU, Sigma-Aldrich) was injected i.p. at $100 \mathrm{mg} \mathrm{kg}^{-1}$ for 1 or 3 days. All animals had access to water and food ad libitum, in a $12: 12 \mathrm{~h}$ light/dark cycle. The Bioethical Committee of Pontificia Universidad Católica de Chile approved all procedures involving experimentation on animal subjects.

2.2. Perfusion and Postfixation. Animals were anesthetized $(100 \mu \mathrm{g}$ ketamine $+10 \mu \mathrm{g}$ xylazine in $10 \mu \mathrm{L}$ saline/g) and then transcardially perfused with saline, followed by $4 \%$ paraformaldehyde (PFA, Sigma-Aldrich) in PBS. The brain was removed and placed in a vial with 4\% PFA in PBS for $24 \mathrm{~h}$ at room temperature, dehydrated in $30 \%$ sucrose, and kept at $4^{\circ} \mathrm{C}$ until analysis.

2.3. Tissue Sectioning. After dehydration, brains were sectioned on a cryostat in 12 sets of serial coronal slices of
$40 \mu \mathrm{m}$ thickness (Leica Microsystems) and collected in icecold PBS in multiwell dishes as previously described [26]. Each set contained 5-7 slices covering the entire length of the hippocampus and therefore corresponds to a representative sampling of the whole hippocampus.

2.4. Immunofluorescence. Immunodetection of BrdU and neuronal markers in tissue sections was carried out as previously described in [26]. Primary antibodies used were rat anti-BrdU (Abcam), rabbit anti-doublecortin (Cell Signaling Technology Inc.), monoclonal anti-NeuN (Millipore, Billerica, MA, USA), rabbit anti-Ki67 (Abcam), goat anti-NeuroD1 (Santa Cruz Biotechnology, Inc.), monoclonal anti-Nestin (Millipore), Alexa (Molecular Probes, Life Technologies), and DyLight (Abcam) conjugated secondary antibodies were used. Slices were mounted on gelatin-coated slides with Fluoromount-G (Electron Microscopy Sciences).

2.5. Image Analysis. For quantification, BrdU, Ki67, or DCXpositive cells were counted using a fluorescence microscope (Olympus BX51, Tokyo, Japan) as described in [26]. Briefly, total numbers of cells counted in all sections of 1 set of brain tissues (see tissue sectioning) were multiplied by the total number of sets to estimate the total number of BrdU, Ki67, or DCX-positive cells in the complete SGZ (BrdU and Ki67) or GCL (DCX). Double-labeled sections were analyzed by confocal laser microscopy (Olympus FV 1000). Image analysis and z-projections were made with ImageJ software (NIH, USA).

In APPswe/PSEN1 $\triangle \mathrm{E} 9$, the density of DCX-positive cells was estimated as previously described by Lie et al. [20] with some modifications. Briefly, DCX-positive cells in the GCL were counted in series of 5-6 random sections. NeuN immunoreactivity was used to measure the GCL volume. The area of the GCL was traced by using ImageJ software and a 10x objective. The density of immature neurons was expressed as DCX cells per volume $\left(\mathrm{mm}^{3}\right)$ of dentate GCL.

2.6. Immunoblotting. Hippocampi were dissected on ice and either immediately frozen in liquid nitrogen or processed as previously described [27]. Briefly, hippocampi were homogenized in RIPA buffer $(10 \mathrm{mM}$ Tris/ $\mathrm{HCl} \mathrm{pH} 7.4,5 \mathrm{mM}$ EDTA, 1\% NP-40, 1\% sodium deoxycholate, and 1\% SDS) supplemented with a protease inhibitor mixture (1 mM PMSF, $2 \mu \mathrm{g} / \mathrm{mL}$ aprotinin, $1 \mu \mathrm{g} / \mathrm{mL}$ pepstatin, and $10 \mu \mathrm{g} / \mathrm{mL}$ benzamidine) and phosphatase inhibitors (25 mM NaF, $100 \mathrm{mM}$ $\mathrm{Na}_{3} \mathrm{VO}_{4}, 1 \mathrm{mM}$ EDTA, and $30 \mu \mathrm{M} \mathrm{Na} \mathrm{P}_{2} \mathrm{O}_{7}$ ), maintained on ice for $30 \mathrm{~min}$ before centrifugation at 20,000 $\mathrm{g}$ for $15 \mathrm{~min}$ at $4^{\circ} \mathrm{C}$. Protein concentration in supernatants was determined using the BCA Protein Assay Kit (Pierce). Proteins were resolved in $10 \%$ SDS/PAGE, transferred to a PVDF membrane, reacted with primary antibodies overnight at $4^{\circ} \mathrm{C}$, and then incubated with peroxidase-conjugated secondary antibodies (Pierce) and developed using the ECL technique (Western Lightning Plus ECL, PerkinElmer). Primary antibodies used were mouse anti- $\beta$-catenin, rabbit anti-GSK-3 $\beta$, goat anti-NeuroD1, rabbit anti- $\beta$-tubulin (all from Santa Cruz 
Biotechnology, Inc.), and rabbit anti-GSK-3 $\beta$ pSer9 (Cell Signalling).

2.7. Statistical Analysis. Statistical analysis was performed using Prism 5 software (GraphPad Software Inc.). Statistical significance of differences was assessed using the unpaired Student's $t$-test; nonnormally distributed data was analyzed using the Mann-Whitney test. The number of animals per group in each experiment is indicated in the figure legends.

\section{Results}

3.1. ANDRO Stimulates Cell Proliferation in the SGZ of Adult Mice. To evaluate the effect of ANDRO on adult hippocampal neurogenesis, we first analyzed the effect of the drug on cell proliferation in the SGZ. Two-month-old mice were injected i.p. with $2 \mathrm{mg} \mathrm{kg}^{-1}$ ANDRO or vehicle as control, 3 times a week for 4 weeks. In the last day of the treatment, animals also received in the i.p. injection a single dose of the nucleotide analog $\mathrm{BrdU}\left(100 \mathrm{mg} \mathrm{kg}^{-1}\right)$ and were sacrificed $24 \mathrm{~h}$ after the injection. The effect in cell proliferation was investigated by nuclear incorporation of BrdU (Figure 1(a)) and Ki67 staining (Figure 1(b)) used as a mitotic marker. BrdU immunoreactivity revealed that there was a significant increase in the total number of BrdU-positive cells in the SGZ of ANDRO-treated mice (Figure 1(a)) compared to control mice injected with the vehicle (control: 1,726 \pm 196 , ANDRO: $2,554 \pm 275 ; P=0.027)$. Also, there was a significant increase in the total number of Ki67-positive cells in the SGZ of mice treated with ANDRO compared to control mice (Figure 1(c), control: $2,341 \pm 86$, ANDRO: $3,711 \pm 344 ; P=0.001$ ). These results indicate that ANDRO stimulates proliferation in the SGZ of adult mice.

Also, we evaluated the effect of ANDRO on cell proliferation in mice aged 10 months which show reduced levels of neurogenesis due to an age-related decline in neurogenesis observed in several species [28-31]. These mice were injected i.p. with $2 \mathrm{mg} \mathrm{kg}^{-1}$ ANDRO or vehicle as control, 3 times a week for 4 weeks; proliferation in the SGZ was evaluated by Ki67 staining. As expected, there was a strong decrease in Ki67-positive cells in 10-month-old mice compared with 2-month-old-mice (Figures 1(c) and 1(d)), and there was a significant increase in total number of Ki67-positive cells in mice treated with ANDRO (Figure 1(d), control: $269 \pm$ 12, ANDRO: $470 \pm 54 ; P=0.011$ ). Altogether, these results indicate that ANDRO increases cell proliferation in the dentate gyrus of young and aged mice.

3.2. ANDRO Increases Proliferation of Neural Progenitor Cells in the Adult Mouse Hippocampus. The increased number of BrdU- and Ki67-positive cells may result from increased proliferation of neural progenitor cells or neuroblasts. To evaluate whether quiescent neural progenitor cells are cellular targets of ANDRO, we evaluated Ki67 staining in Nestinpositive cells within the SGZ (Figure 2). Nestin is an intermediate filament expressed in neural progenitors but not in neuroblasts $[32,33]$. Mice treated with $2 \mathrm{mg} \mathrm{kg}^{-1}$ ANDRO for 4 weeks showed a significant increase of Nestin+Ki67+ cells compared to vehicle-treated animals (Figure 2, control:
$584 \pm 112$, ANDRO: $1,956 \pm 343 ; P=0.0191$ ), indicating that the drug induced the activation of neural progenitors in the SGZ.

3.3. ANDRO Increases Neurogenesis in the Dentate Gyrus of Adult Mice. To evaluate whether ANDRO treatment induced the generation of new neurons in the adult dentate gyrus, first we carried out immunodetection of the immature neuronal marker doublecortin (DCX). A strong increase in the density of immature neurons positive for DCX was observed in the dentate gyrus of 2-month-old mice treated for 4 weeks with $2 \mathrm{mg} \mathrm{kg}^{-1}$ ANDRO compared with control mice injected with the vehicle (Figures 3(a) and 3(b)). Immunodetection of DCX was also carried out in 10-month-old mice that received the same treatment (Figure 3(c)). In agreement with the age-dependent decline in neurogenesis, there was an evident decrease in the density of immature DCX-positive neurons in mice aged 10 months compared with 2-monthold animals (compare Figures 3(a) and 3(c)). In 10-monthold mice, ANDRO treatment induced a significant increase in the total number of DCX-positive cells in the GCL compared with control mice injected with vehicle solution (Figure 3(c), control: $1,246 \pm 108$, ANDRO: $2,141 \pm 250 ; P=0.008$ ).

To further evaluate whether ANDRO induced a net increase in neurogenesis, 2-month-old mice were injected i.p. with $2 \mathrm{mg} \mathrm{kg}^{-1}$ ANDRO or vehicle as control, 3 times a week for 2 weeks, and then received a daily i.p. injection of $100 \mathrm{mg} \mathrm{kg}^{-1} \mathrm{BrdU}$ for 3 consecutive days and then continued with the injections of $2 \mathrm{mg} \mathrm{kg}^{-1}$ ANDRO or vehicle 3 times a week for 4 additional weeks (Figure 4(a)). As it was observed in the treatment of 4 weeks (Figure 1(c)), after 6 weeks of treatment there was a significant increase in the total number of Ki67-positive cells in the SGZ of mice treated with ANDRO compared with control mice (Figure 4(b); control: 1,784 \pm 86 , ANDRO: $2,888 \pm 152 ; P=0.0049$ ), supporting the effect of the drug on cell proliferation. To assess the effect in neurogenesis, we evaluated the total number of newborn granule cells by analyzing the total number of BrdU-positive cells that were also positive for the mature neuronal marker NeuN. This was evaluated by confocal microscopy using z-plane sections to assess NeuN staining in each BrdU-positive cell (Figure 4(c), insets) and the total number of $\mathrm{BrdU}+\mathrm{NeuN}+$ cells was estimated in the whole dentate gyrus [26]. A significant increase was observed in the total number of BrdU+NeuN+ cells in the GCL of mice treated with ANDRO compared with control mice (Figure 4(d), control: $477 \pm 84$, ANDRO: $1,023 \pm 108, P=0.0286$ ), indicating that ANDRO increased the generation of new granule neurons in the dentate gyrus. Altogether, these findings indicate that ANDRO increases neurogenesis in the adult hippocampus.

\subsection{ANDRO Stimulates the Wnt/ $\beta$-Catenin Signaling Pathway} in the Hippocampus of Adult Mice. We previously showed that ANDRO inhibits the activity of GSK-3 $\beta$ [9], a component of the Wnt/ $\beta$-catenin signaling pathway that upon activation of the pathway is inhibited, thereby preventing the phosphorylation of its target $\beta$-catenin which is translocated into the nucleus to activate the transcription of Wnt target 

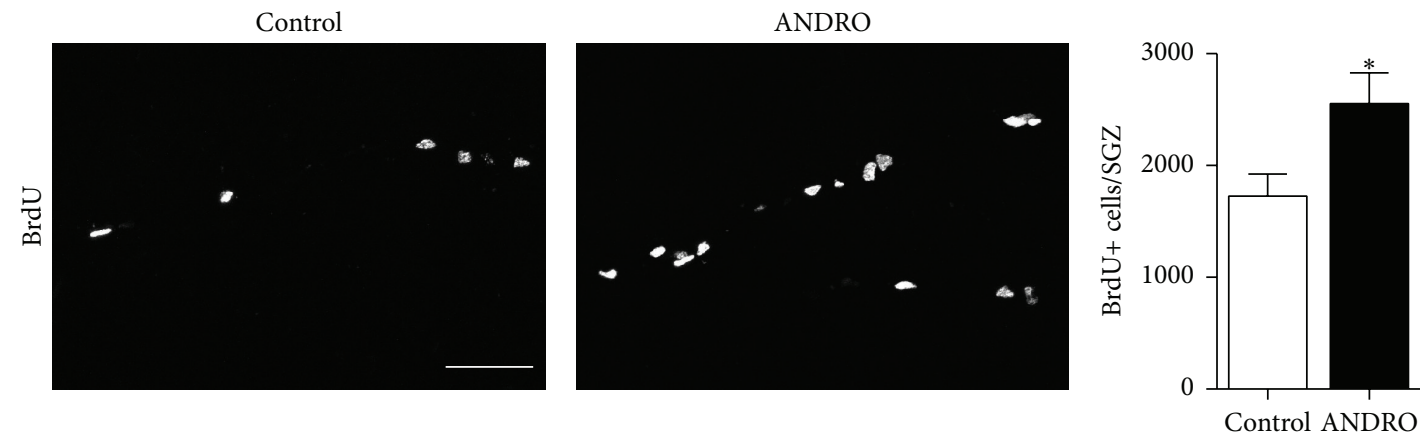

(a)
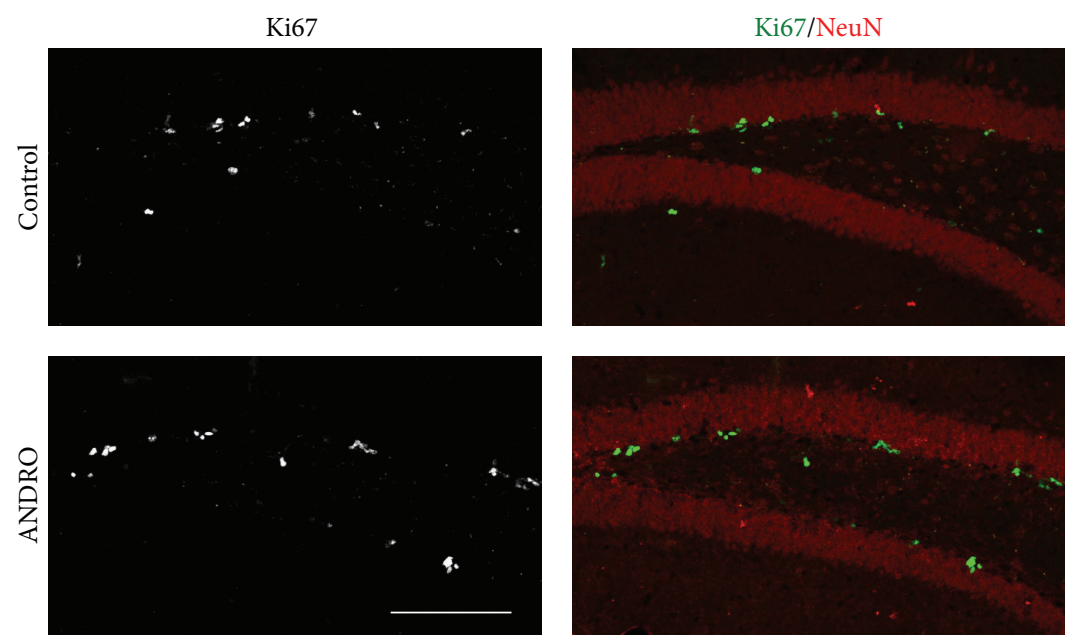

(b)

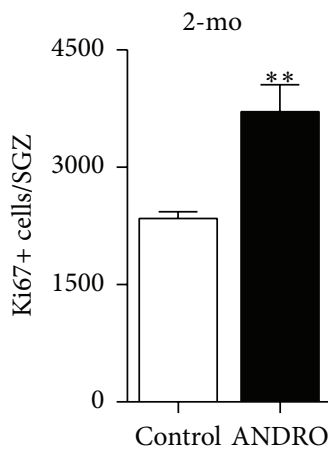

(c)

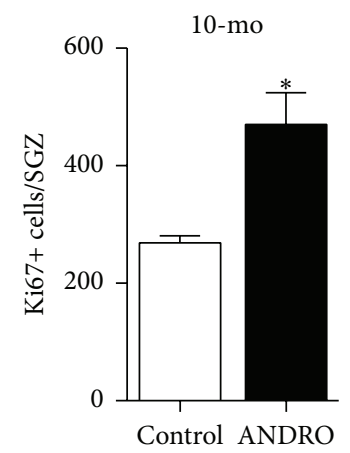

(d)

FIGURE 1: ANDRO induces proliferation in the dentate gyrus of adult mice. Two-month-old mice were injected i.p. with 2 mg kg ${ }^{-1}$ ANDRO or vehicle as control 3 times a week for 4 weeks, received a single dose of $100 \mathrm{mg} \mathrm{kg}^{-1} \mathrm{BrdU}$ the last day of treatment, and were sacrificed $24 \mathrm{~h}$ after BrdU injection. (a) Images show representative immunostaining of BrdU. Scale bar: $50 \mu \mathrm{m}$. The graph shows total number of BrdUpositive (BrdU+) cells in the whole SGZ of control and ANDRO-treated mice. Bars represent mean \pm S.E. $(n=7$ mice). (b) Representative immunostaining of Ki67 and NeuN. Scale bar: $100 \mu \mathrm{m}$. (c, d) Total number of Ki67-positive (Ki67+) cells in the SGZ of control and ANDROtreated 2-month-old (c) or 10-month-old (d) mice. Bars represent mean \pm S.E. $\left(n=7\right.$ (c) and $n=5$ (d) mice). ${ }^{*} P<0.05,{ }^{* *} P<0.01$, Student's $t$-test.

genes [34]. We evaluated the activation of the Wnt signaling pathway in the hippocampus of 2-month-old mice injected i.p. with $2 \mathrm{mg} \mathrm{kg}^{-1}$ ANDRO or vehicle as control, 3 times a week for 4 weeks. As expected, we observed a significant increase in $\beta$-catenin level in the hippocampus of ANDROtreated animals compared with control mice (Figure 5(a)), concomitantly with an increase in the level of the inactive form of GSK- $3 \beta$ phosphorylated in serine- 9 residue (Figure 5(a)). In addition, we evaluated the levels of NeuroD1 which is a transcription factor involved in neurogenesis in the embryonic and adult brain [35] that was previously identified as a Wnt target gene [24]. A significant increase of 

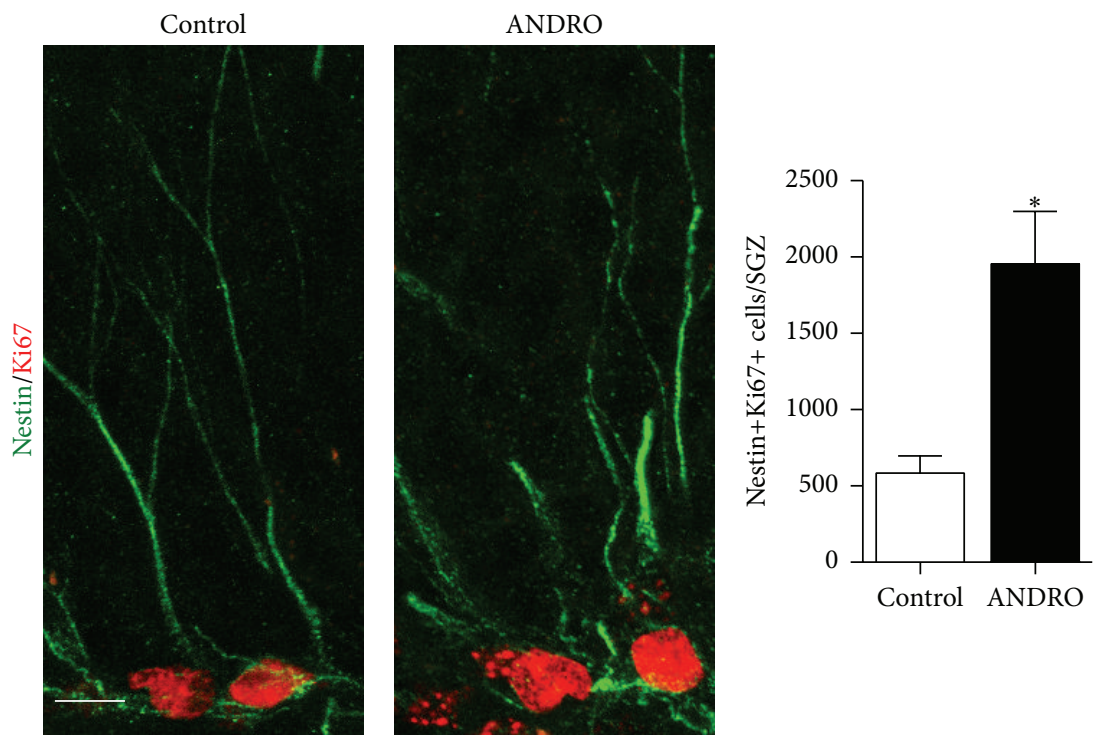

FIGURE 2: ANDRO induce proliferation of neural progenitors in the SGZ. Representative immunostaining of Ki67 and Nestin in 2-month old mice treated per 4 weeks with $2 \mathrm{mg} \mathrm{kg}^{-1}$ ANDRO or saline solution as control. Scale bar: $10 \mu \mathrm{m}$. The graph represents quantification of the total number of Ki67-positive/Nestin-positive $($ Ki67+Nestin +$)$ cells in the SGZ. Bars represent mean \pm S.E. $\left(n=3\right.$ mice). ${ }^{*} P<0.05$, Student's $t$-test.

NeuroD1 level was observed in the hippocampus of ANDROtreated mice (Figure 5(b)). This increase was also observed by immunostaining (Figure 5(c)), in which NeuroD1 was mainly observed in DCX-positive cells, as previously described [35]. Altogether, these findings indicate that ANDRO induces the activation of the Wnt $/ \beta$-catenin signaling pathway in the hippocampus of adult mice.

3.5. ANDRO Increases Neurogenesis in the Dentate Gyrus of APPswe/PSEN1 $1 E 9$ Mice. Finally, we evaluated the effect of ANDRO on neurogenesis in APPswe/PSEN1 $\triangle \mathrm{E} 9$ transgenic mouse model of $\mathrm{AD}$ that shows an impaired neurogenesis [26]. These double transgenic animals express the human amyloid precursor protein (APP) with the Swedish mutation (K595N/M596L) and presenilin 1 with the deletion of exon 9 and show histopathological hallmarks of $\mathrm{AD}$ (e.g., $\mathrm{A} \beta$ deposition, amyloid plaques, astrogliosis, and tau pathology) and cognitive impairment by 7 months of age [27]. We determined that at this age animals show a significant reduction in cell proliferation in the SGZ and show an impaired differentiation of newborn cells into DCX-positive neuroblasts [26]. APPswe/PSEN1 $\triangle \mathrm{E} 9$ mice at 7 months were injected i.p. with $2 \mathrm{mg} \mathrm{kg}^{-1}$ ANDRO or vehicle as control, 3 times a week for 4 weeks. Proliferation at the SGZ was evaluated by Ki67 staining (Figure 6(a)). Treatment with ANDRO strongly induced proliferation as determined by the increased number of Ki67-positive cells (APPswe/PSEN1 $\triangle \mathrm{E} 9$ control: $96 \pm 37$, APPswe/PSEN1 $\triangle$ E9 ANDRO $256 \pm 32$; $P=0.05)$. In addition, an increased density of immature DCX-positive neurons was observed in mice treated with ANDRO compared to control transgenics that received vehicle injections (Figure 6(b)), indicating that the drug induced neurogenesis in APPswe/PSEN1 $\triangle \mathrm{E} 9$.
In these mice, we also evaluated the Wnt target gene NeuroD1 (Figure 7(a)). As we previously observed in 12month-old transgenic mice [8], increased levels of $\beta$-catenin and GSK- $3 \beta$ phosphorylated in serine-9 were observed in APPswe/PSEN1 $\triangle$ E9 mice treated with ANDRO compared with control mice (Figure 7(b)). In addition, and as observed in wild-type animals (Figure 5(b)), ANDRO treatment induced a significant increase of NeuroD1 level at the hippocampus of APPswe/PSEN1 $\triangle \mathrm{E} 9$ mice (Figure 7(c)).

\section{Discussion}

The generation of new neurons in the hippocampus during adulthood has been determined in several species and has shown to contribute to the plasticity of the hippocampus and to some hippocampal processes including spatial learning and memory $[17,19]$. This process is compromised in several pathologies affecting the central nervous system (e.g., $\mathrm{AD}$, schizophrenia, and mood disorders) and also is affected during normal aging $[30,36]$; the decreased neurogenesis has been linked, for example, to cognitive deficits associated with some of these conditions; therefore, it is tempting to search for new approaches to stimulate this process in normal and diseased brain. Here, we evaluated the ability of ANDRO, one of the active components of the medicinal plant Andrographis paniculata, to stimulate neurogenesis, and demonstrated that ANDRO induces proliferation and the generation of new neurons in the dentate gyrus of the adult hippocampus in wild-type mice and in a mouse model of $\mathrm{AD}$.

In the adult dentate gyrus, new granule cells are continuously being generated from neural progenitor cells that are located between the hilus and the GCL. After activation, these cells give rise to transit-amplifying progenitors or 

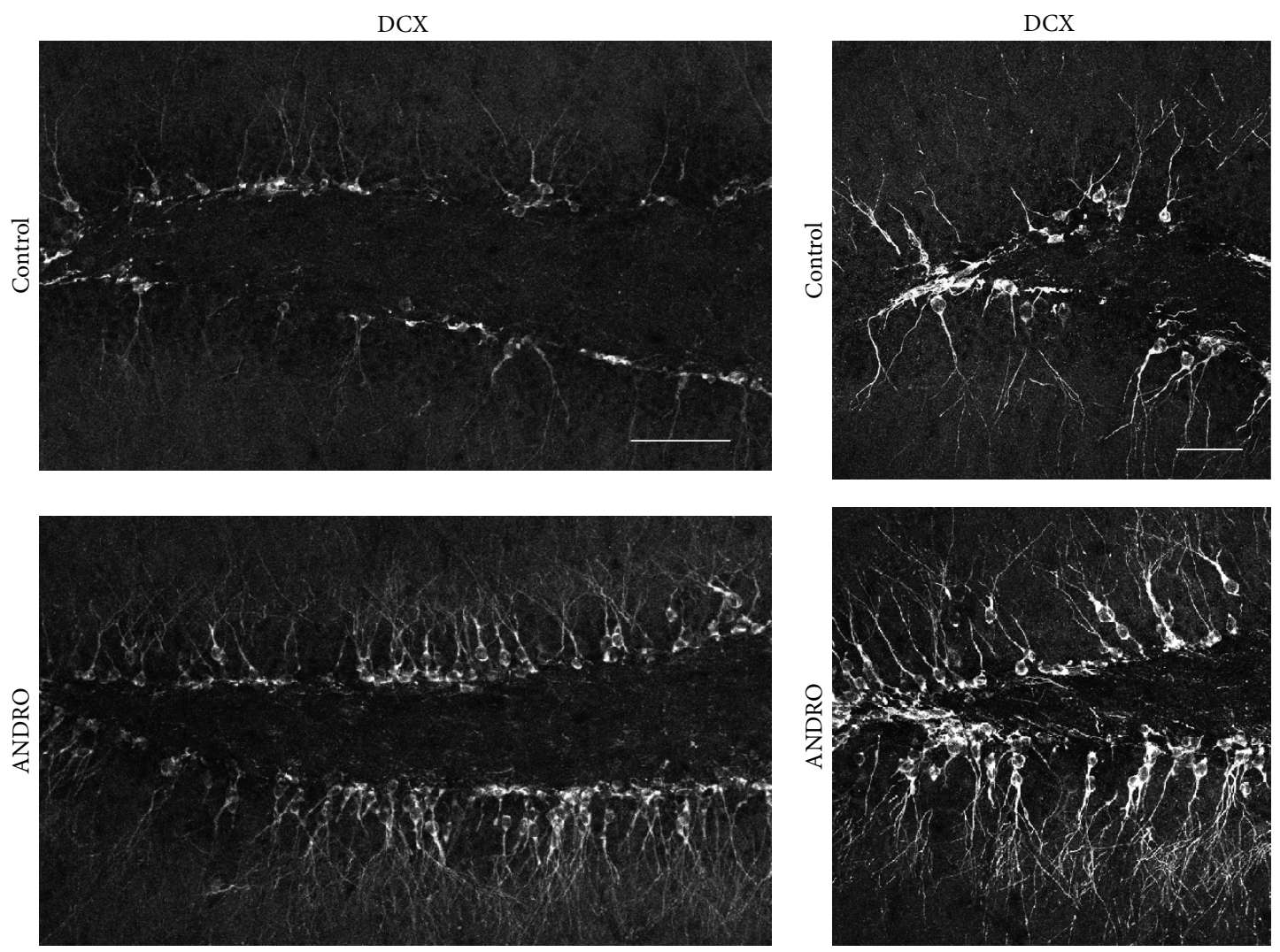

(a)

(b)
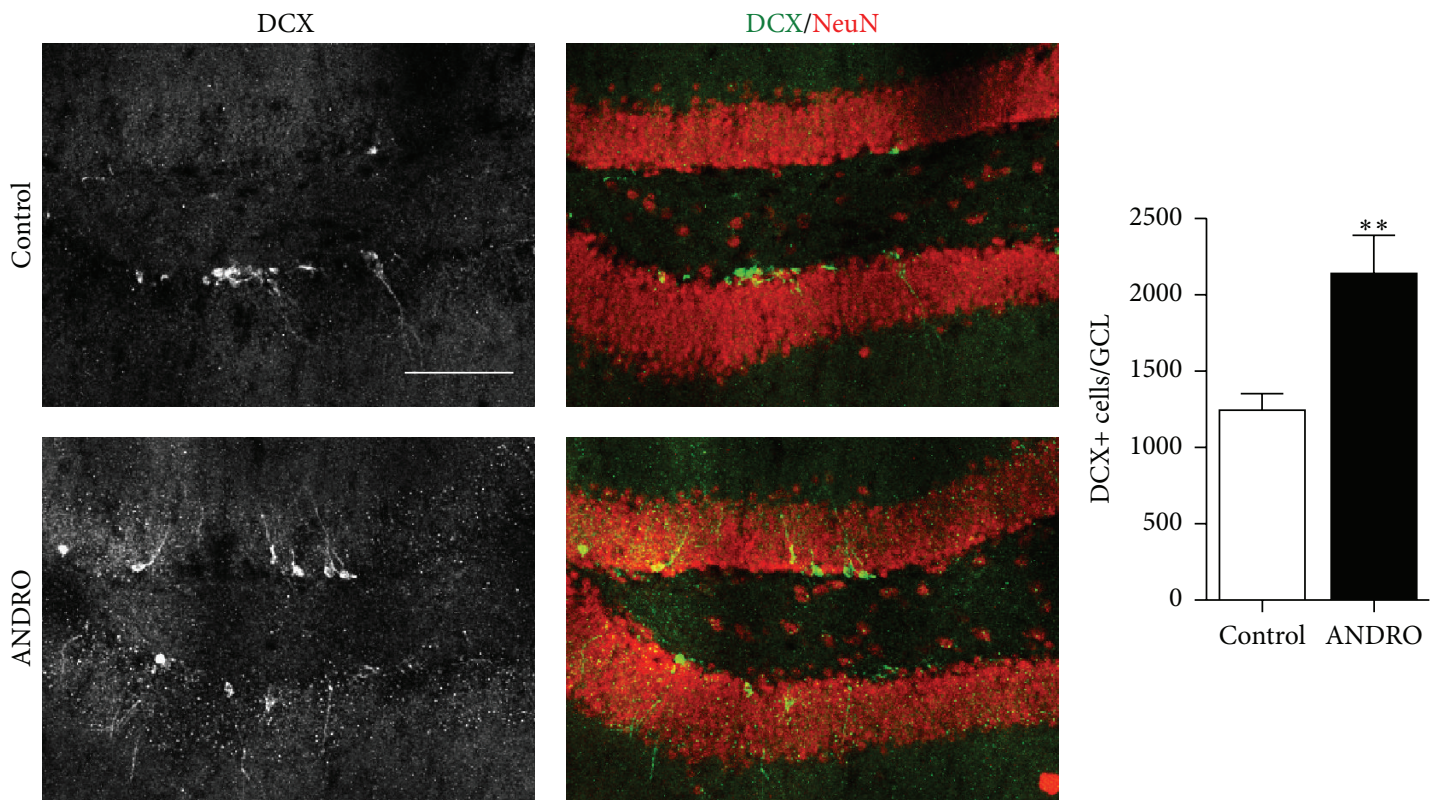

(c)

FIGURE 3: ANDRO increases the density of immature neurons in the dentate gyrus of adult mice. (a) Representative immunostaining of DCX in 2-month-old mice treated with vehicle or ANDRO for 4 weeks. Scale bar: $50 \mu \mathrm{m}$. (b) Higher magnification of representative DCX immunostaining in control and ANDRO-treated mice. Scale bar: $30 \mu \mathrm{m}$. (c) Representative images of double immunostaining for DCX and NeuN in 10-month-old mice treated with vehicle or ANDRO for 4 weeks. Scale bar: $100 \mu \mathrm{m}$. Graph quantification of total number of DCXpositive $(\mathrm{DCX}+)$ cells in the GCL 10 -month-old mice. Bars represent mean \pm S.E. $\left(n=5\right.$ mice). ${ }^{* *} P<0.01$, Student's $t$-test. 


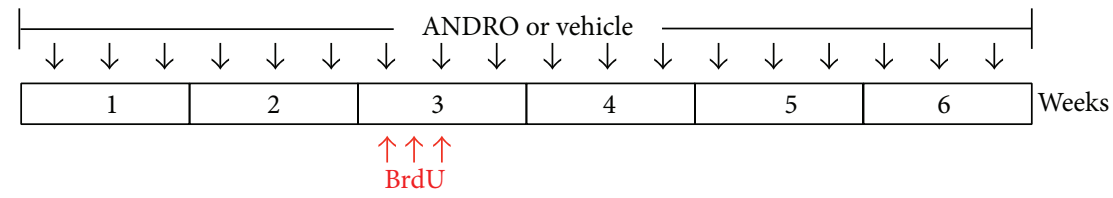

(a)
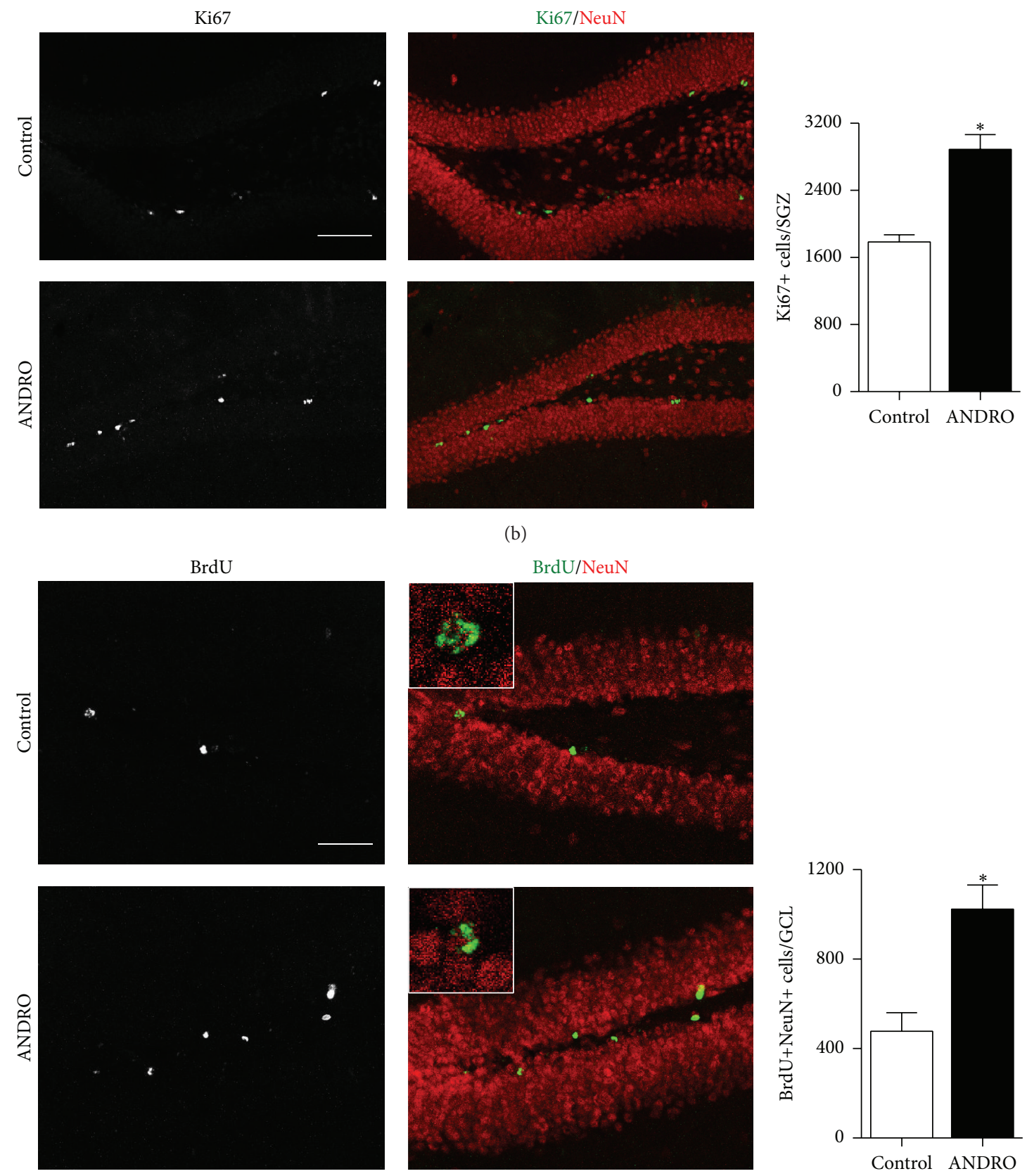

(c)

(d)

FIGURE 4: ANDRO increases the generation of newborn granule cells in the hippocampus of adult mice. (a) Schematic representation of the experimental procedure. Two-month-old mice were injected i.p. with $2 \mathrm{mg} \mathrm{kg}^{-1}$ ANDRO or vehicle as control 3 times a week for 2 weeks and then received a daily i.p. injection of $100 \mathrm{mg} \mathrm{kg}^{-1} \mathrm{BrdU}$ for 3 consecutive days and continued with the treatments for 4 weeks. (b) Representative immunostaining of Ki67 and NeuN after 6 weeks of treatment. Scale bar: $100 \mu \mathrm{m}$. The graph represents quantification of the total number of Ki67-positive (Ki67+) cells in the SGZ. (c) Representative immunostaining of BrdU and NeuN. Insets show higher magnifications of doublepositive cells. Scale bar: $50 \mu \mathrm{m}$ (d) Quantification of the total number of double-positive (BrdU+NeuN+) cells in the GCL of control and ANDRO-treated mice. Bars represent mean \pm S.E. $(n=4$ mice $){ }^{*} P<0.05$, Student's $t$-test. 


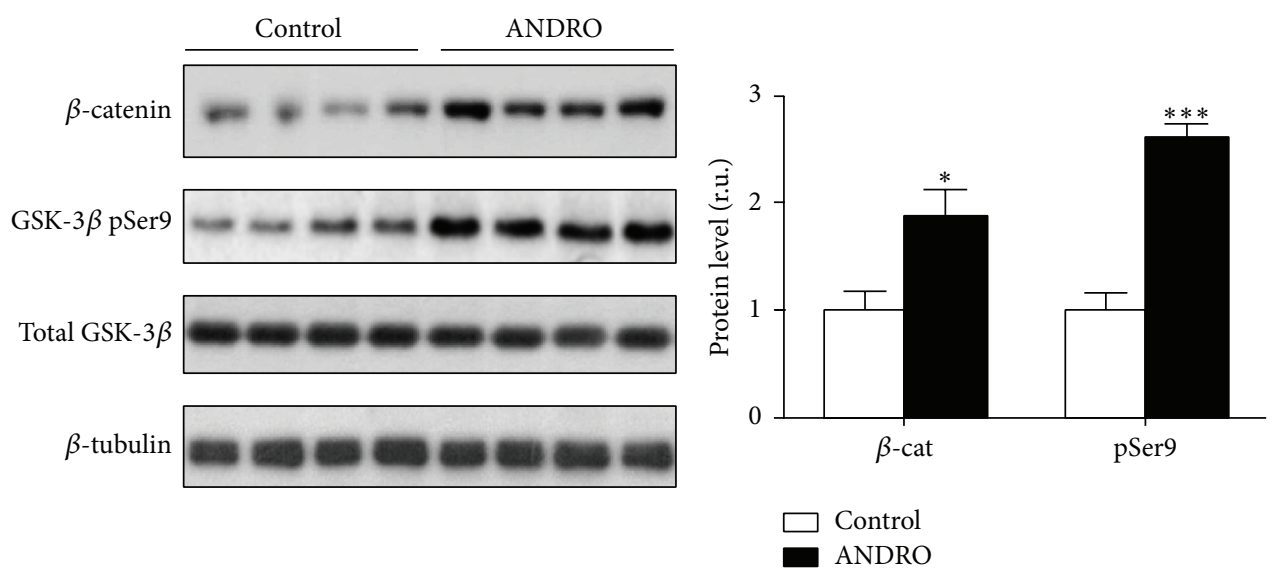

(a)

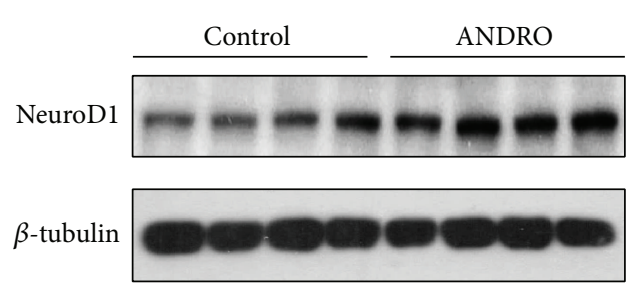

(b)
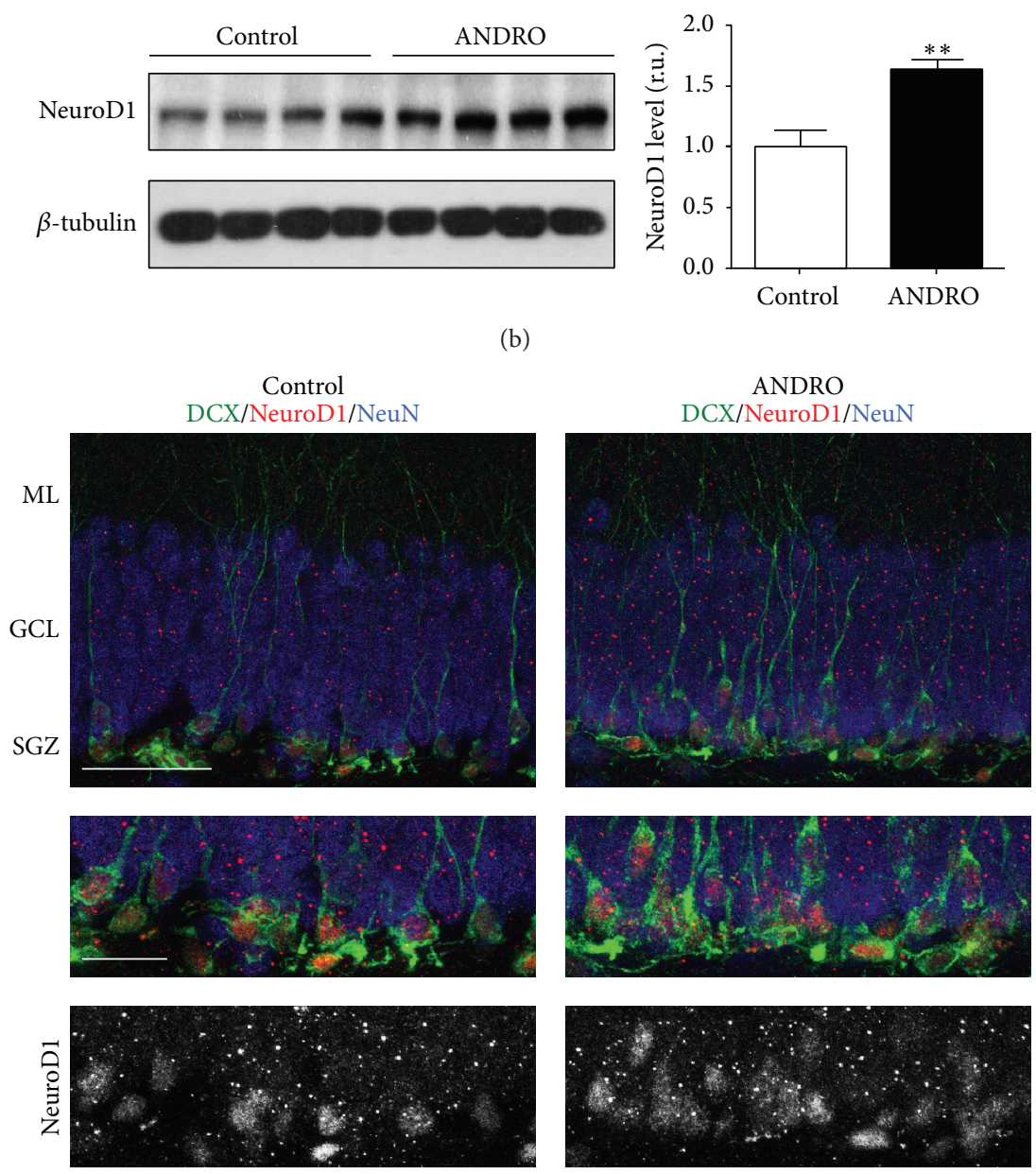

(c)

FIGURE 5: ANDRO induces the activation of the Wnt signaling pathway in the hippocampus of adult mice. (a) Immunoblots of $\beta$-catenin, inactive form of GSK-3 $\beta$ (phosphorylated in serine-9, pSer9), total GSK-3 $\beta$, and $\beta$-tubulin used as loading control in total protein extracts obtained from the hippocampus of 2-month-old mice injected i.p. with $2 \mathrm{mg} \mathrm{kg}^{-1}$ ANDRO or vehicle as control 3 times a week for 4 weeks. The graph corresponds to the densitometric analysis of $\beta$-catenin and GSK- $3 \beta$ pSer9 normalized to $\beta$-tubulin and total GSK-3 $\beta$, respectively. (b) Immunoblot of NeuroD1 and $\beta$-tubulin. The graph corresponds to the densitometric analysis of NeuroD1 normalized to $\beta$-tubulin level. (c) Representative immunostaining of NeuroD1, DCX, and NeuN in mice treated with vehicle or ANDRO for 4 weeks. Scale bar: $20 \mu \mathrm{m}$. Bottom, higher magnifications of the images. Scale bar: $20 \mu \mathrm{m}$. Bars represent mean \pm S.E. $(n=4$ mice $) .{ }^{*} P<0.05,{ }^{* *} P<0.01$, and ${ }^{* * *} P<0.001$, Student's $t$-test. 

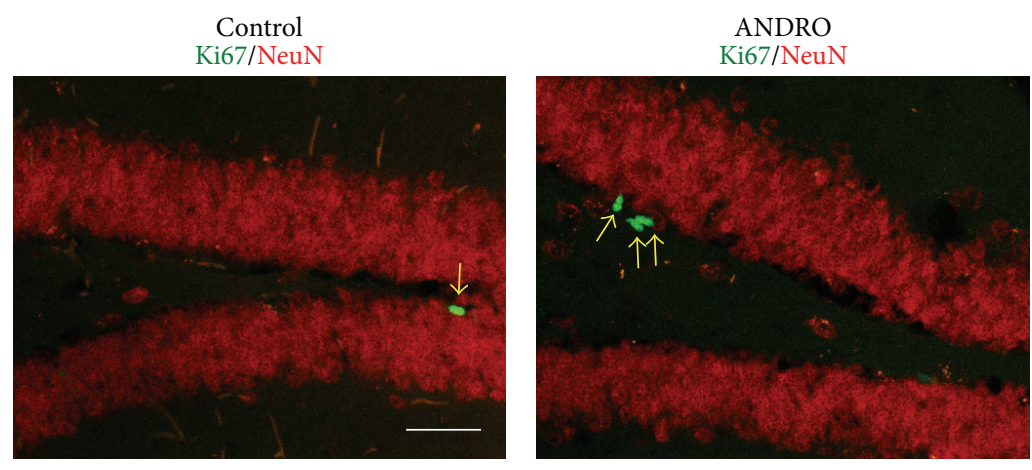

(a)
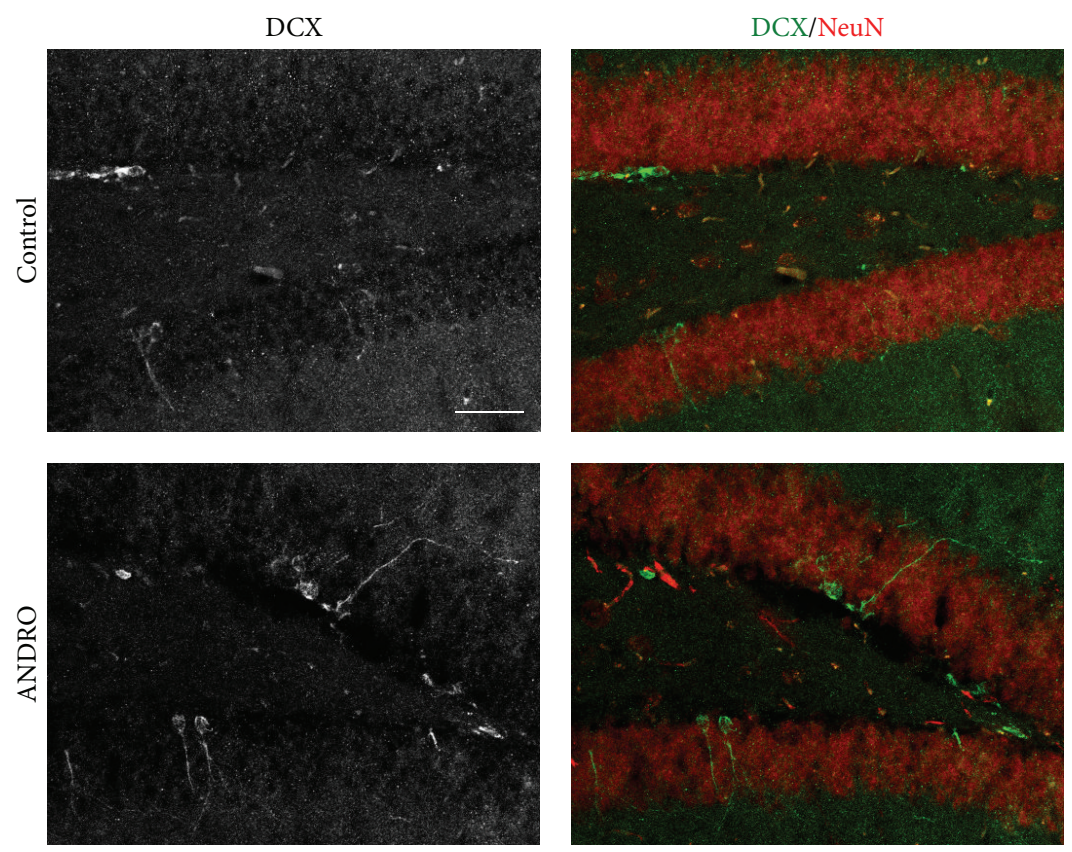

(b)
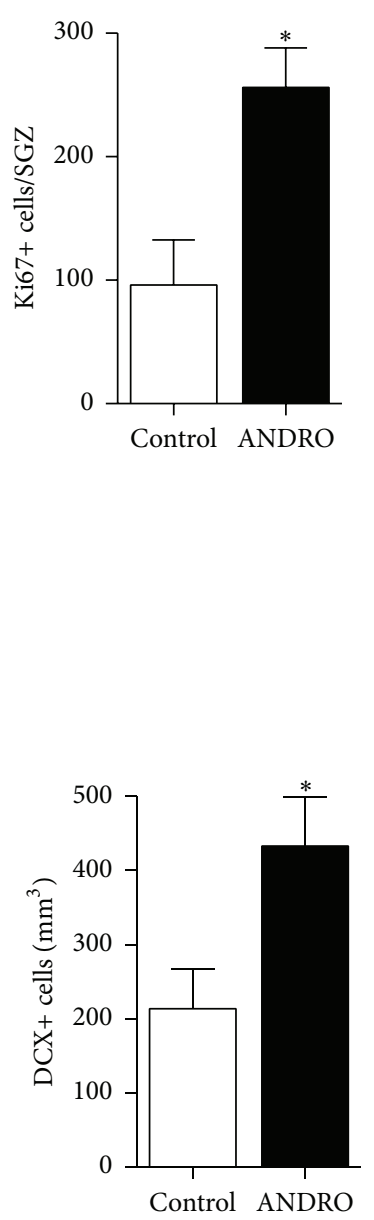

FIGURE 6: ANDRO stimulates proliferation and the density of immature neurons in the dentate gyrus of APPswe/PSEN1 $\triangle$ E9. Seven-monthold APPswe/PSEN1 $\triangle \mathrm{E} 9$ mice were injected i.p. with $2 \mathrm{mg} \mathrm{kg}^{-1}$ ANDRO or vehicle as control 3 times a week per 4 weeks. (a) Representative images of double immunostaining for Ki67 and NeuN. The graph shows quantification of the total number of Ki67-positive (Ki67+) cells (yellow arrows) in the SGZ of mice treated with vehicle or ANDRO. Scale bar: $20 \mu \mathrm{m}$. (b) Images show representative double immunostaining for DCX and NeuN. Scale bar: $20 \mu \mathrm{m}$. Graph differences in the density of immature DCX-positive (DCX+) neurons in control and ANDROtreated APPswe/PSEN1 $\triangle$ E9 mice. Bars represent mean \pm S.E. $\left(n=3\right.$ (a) or $n=5$ (b) mice). ${ }^{*} P<0.05$, Student's $t$-test.

intermediate progenitor cells that then commit to the neuronal fate generating neuroblasts that develop into immature neurons that extend dendrites to the GCL and molecular layer and project their axons to the CA3 region [16]. These newborn neurons will mature during several weeks into functional dentate granule neurons that form synaptic connections and become integrated into the hippocampal circuitry [37, 38]. We determined that ANDRO treatment for 4 weeks stimulated proliferation in the SGZ and increased the density of immature neurons in the GCL. Our results showed that ANDRO increased the activation of quiescent neural progenitor cells, strongly suggesting that these are the cellular target of ANDRO activity. Interestingly, the effects of ANDRO on proliferation and immature neurons were observed in mice aged 2 months at the beginning of the treatment and also in mice at 10 months of age where neurogenesis is significantly reduced. An age-dependent decline in hippocampal neurogenesis has been evidenced in different species including humans [28-31]; however, studies reveal that neurogenesis can be stimulated even at advanced stages of aging. The effect of ANDRO in 10-month-old mice indicates that the drug is able to stimulate neurogenesis in aged mice. Moreover, we determined that ANDRO induced a net increase in neurogenesis. The expression of mature neuronal markers by newborn neurons takes about four weeks [16]; we determined that ANDRO increased the total number of newborn cells expressing the mature neuronal marker NeuN (evaluated four weeks after administration of 


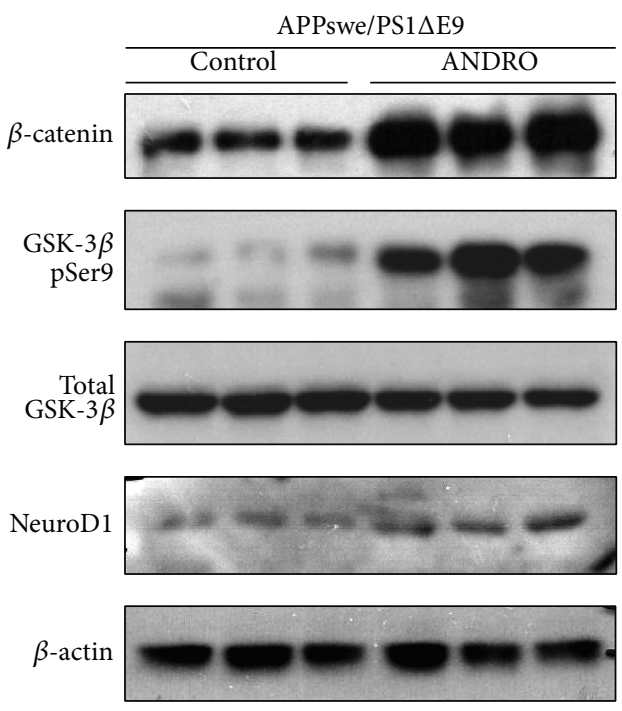

(a)

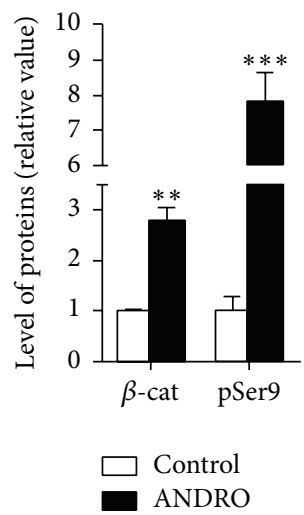

(b)

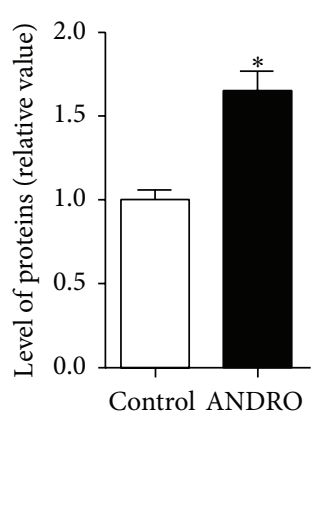

(c)

FIGURE 7: ANDRO increases NeuroD1 in the hippocampus of APPswe/PSEN1 $\Delta E 9$. Seven-month-old APPswe/PSEN1 $\Delta E 9$ mice were injected i.p. with $2 \mathrm{mg} \mathrm{kg}^{-1}$ ANDRO or vehicle as control 3 times a week per 4 weeks. (a) Immunoblots of $\beta$-catenin, inactive form of GSK-3 $\beta$ (phosphorylated in serine-9, pSer9), total GSK-3 $\beta$, NeuroD1, and $\beta$-actin in total protein extracts obtained from the hippocampus of control and ANDRO-treated APPswe/PSEN1 $\triangle E$ 9 mice. (b) Densitometric analysis of $\beta$-catenin and GSK-3 $\beta$ pSer9 normalized to $\beta$-tubulin and total GSK-3 $\beta$, respectively. (c) Densitometric analysis of NeuroD1 normalized to $\beta$-tubulin. Bars represent mean \pm S.E. $\left(n=3\right.$ mice). ${ }^{*} P<0.05$, ${ }^{* *} P<0.01$, and ${ }^{* * *} P<0.001$, Student's $t$-test.

BrdU), indicating that the drug induced a net increase in the total number of newly born granule neurons. Altogether, these findings indicate that ANDRO stimulates neurogenesis in the adult hippocampus.

The effect of ANDRO on neurogenesis may involve the inhibition of GSK-3 $\beta$. We recently determined that ANDRO inhibits GSK- $3 \beta$ by a substrate-competitive mode of action [9]. Interestingly, ANDRO shows high selectivity for GSK-3 $\beta$, since it had no effect on cyclin-dependent kinase 5 (Cdk5), $\mathrm{Ca}^{2+} /$ calmodulin-dependent protein kinase II (CaMKII), extracellular signal-regulated kinase (ERK), cJun N-terminal kinase (JNK), protein kinase C (PKC), Akt, casein kinase (CK), and S6 kinase [9]. Stimulation of neurogenesis by GSK-3 $\beta$ inhibition has been reported in vitro and in vivo. Treatment of cultured adult hippocampal progenitors with the GSK-3 $\beta$ inhibitor lithium induced proliferation [39] and in vivo treatment with lithium induced proliferation and neuronal fate specification in the hippocampus of a mouse model of $\mathrm{AD}$ [40]. In addition, an impaired neurogenesis was observed in a GSK-3 knock-in mouse carrying mutations to block inhibitory phosphorylation of the kinase [41] and in mice overexpressing GSK-3 $\beta$ [42] which also show morphological alterations in newborn neurons [43]. Therefore, it is likely that ANDRO may stimulate neurogenesis via inhibition of GSK-3 $\beta$. Other mechanisms that have been associated with the biological effects of ANDRO include inhibition of PI3K/Akt and NF- $\kappa \beta$ pathways [44-46]. As mentioned, we previously determined that ANDRO has no effect on Akt activity [9], and since inhibition of NF- $\kappa \beta$ signaling pathway is associated with an impaired adult hippocampal neurogenesis $[47,48]$, it is unlikely that the positive effect of ANDRO on neurogenesis may involve these cascades.

As previously mentioned, GSK- $3 \beta$ is a key component of the Wnt/ $\beta$-catenin signaling pathway, which has been 
shown in several in vivo studies to regulate proliferation, differentiation, and maturation of adult-born granule neurons $[20-22,24]$. Through the inhibition of GSK-3 $\beta$, ANDRO is a potent activator of the Wnt signaling pathway [9]. Here, we determined that concomitantly with the increase in neurogenesis ANDRO treatment induced the $\mathrm{Wnt} / \beta$-catenin signaling pathway in the hippocampus of adult mice, as determined by the increase in $\beta$-catenin protein and the increase in the level of the inactive form of GSK-3 $\beta$. In addition, we observed increased level of NeuroD1, a previously described Wnt target gene [24] that is needed for the survival and maturation of adult-born neurons. Therefore, it might be suggested that the effects of ANDRO may be mediated by the activation of the Wnt signaling pathway and the expression of proneural Wnt target genes such as NeuroD1. Interestingly, increased level of NeuroD1 was also observed in ANDRO-treated APPswe/PS1 $\triangle \mathrm{E} 9$ mice. In this mouse model of $\mathrm{AD}$, which shows reduced levels of proliferation in the SGZ and decreased differentiation of neural progenitor cells into neurons compared with age-matched wild-type mice $[26,49]$, we determined that ANDRO treatment induced almost 3-fold increase in cell proliferation in the SGZ. We had observed such a strong effect in cell proliferation in this transgenic mouse by exposure to voluntary wheel running [50], which is a well-known potent inductor of neurogenesis in young and aged mice [51, 52]. Also, we determined that ANDRO treatment increased the density of immature neurons in APPswe/PS1 $\triangle \mathrm{E} 9$ mice, indicating that the drug induced neurogenesis.

\section{Conclusions}

In the present study, we have demonstrated that ANDRO, the active component of the medicinal plant Andrographis paniculata, stimulates adult hippocampal neurogenesis. Previously, ANDRO showed neuroprotective effects in a rat model of permanent cerebral ischaemia [6] and against oxidative damage induced by nicotine [7]; in addition, in the APPswe/PS1 $\triangle \mathrm{E} 9$ mouse model of $\mathrm{AD}, \mathrm{ANDRO}$ prevented neuropathological changes associated with the disease and improved spatial memory [8]. Here, we showed that ANDRO induces proliferation and the generation of new neurons in the adult hippocampus of wild-type and APPswe/PS1 $\triangle$ E9 mice, providing new evidence to suggest ANDRO as a potential therapeutic drug for the treatment of brain diseases.

\section{Conflict of Interests}

All authors declare nonfinancial competing interests.

\section{Acknowledgments}

This work was supported by a Grant from FONDECYT $\left(\mathrm{N}^{\circ} 1150933\right)$ to Lorena Varela-Nallar and by Grants from FONDECYT $\left(\mathrm{N}^{\circ} 1120156\right)$ and the Basal Center of Excellence in Science and Technology (CONICYT-PFB12/2007) to Nibaldo C. Inestrosa.

\section{References}

[1] H. Y. Cheung, C. S. Cheung, and C. K. Kong, "Determination of bioactive diterpenoids from Andrographis paniculata by micellar electrokinetic chromatography," Journal of Chromatography A, vol. 930, no. 1-2, pp. 171-176, 2001.

[2] A. Panossian, A. Hovhannisyan, G. Mamikonyan et al., "Pharmacokinetic and oral bioavailability of andrographolide from Andrographis paniculata fixed combination Kan Jang in rats and human," Phytomedicine, vol. 7, no. 5, pp. 351-364, 2000.

[3] H.-W. Chen, A.-H. Lin, H.-C. Chu et al., "Inhibition of TNFalpha-Induced Inflammation by andrographolide via downregulation of the PI3K/Akt signaling pathway," Journal of Natural Products, vol. 74, no. 11, pp. 2408-2413, 2011.

[4] Y.-F. Xia, B.-Q. Ye, Y.-D. Li et al., "Andrographolide attenuates inflammation by inhibition of NF- $\kappa$ B activation through covalent modification of reduced cysteine 62 of p50," The Journal of Immunology, vol. 173, no. 6, pp. 4207-4217, 2004.

[5] S. Suebsasana, P. Pongnaratorn, J. Sattayasai, T. Arkaravichien, S. Tiamkao, and C. Aromdee, "Analgesic, antipyretic, antiinflammatory and toxic effects of andrographolide derivatives in experimental animals," Archives of Pharmacal Research, vol. 32, no. 9, pp. 1191-1200, 2009.

[6] S. J. Chan, W. S. F. Wong, P. T. H. Wong, and J.-S. Bian, "Neuroprotective effects of andrographolide in a rat model of permanent cerebral ischaemia," British Journal of Pharmacology, vol. 161, no. 3, pp. 668-679, 2010.

[7] S. Das, N. Gautam, S. K. Dey, T. Maiti, and S. Roy, "Oxidative stress in the brain of nicotine-induced toxicity: protective role of Andrographis paniculata nees and vitamin E," Applied Physiology, Nutrition and Metabolism, vol. 34, no. 2, pp. 124-135, 2009.

[8] F. G. Serrano, C. Tapia-Rojas, F. J. Carvajal, J. Hancke, W. Cerpa, and N. C. Inestrosa, "Andrographolide reduces cognitive impairment in young and mature A $\beta$ PPswe/PS-1 mice," Molecular Neurodegeneration, vol. 9, article 61, 2014.

[9] C. Tapia-Rojas, A. Schüller, C. B. Lindsay et al., "Andrographolide activates the canonical Wnt signalling pathway by a mechanism that implicates the non-ATP competitive inhibition of GSK-3 $\beta$ : autoregulation of GSK-3 $\beta$ in vivo," Biochemical Journal, vol. 466, pp. 415-430, 2015.

[10] M. D. Gordon and R. Nusse, "Wnt signaling: multiple pathways, multiple receptors, and multiple transcription factors," The Journal of Biological Chemistry, vol. 281, no. 32, pp. 2242922433, 2006

[11] N. C. Inestrosa and L. Varela-Nallar, "Wnt signalling in neuronal differentiation and development," Cell and Tissue Research, vol. 359, no. 1, pp. 215-223, 2015.

[12] N. C. Inestrosa and E. Arenas, "Emerging roles of Wnts in the adult nervous system," Nature Reviews Neuroscience, vol. 11, no. 2, pp. 77-86, 2010.

[13] P. C. Salinas and Y. Zou, "Wnt signaling in neural circuit assembly," Annual Review of Neuroscience, vol. 31, pp. 339-358, 2008.

[14] L. Varela-Nallar and N. C. Inestrosa, "Wnt signaling in the regulation of adult hippocampal neurogenesis," Frontiers in Cellular Neuroscience, vol. 7, article 100, 2013.

[15] A. Alvarez-Buylla and J. M. García-Verdugo, "Neurogenesis in adult subventricular zone," Journal of Neuroscience, vol. 22, no. 3, pp. 629-634, 2002. 
[16] C. Zhao, W. Deng, and F. H. Gage, "Mechanisms and functional implications of adult neurogenesis," Cell, vol. 132, no. 4, pp. 645660, 2008.

[17] J. S. Snyder, N. Kee, and J. M. Wojtowicz, "Effects of adult neurogenesis on synaptic plasticity in the rat dentate gyrus," Journal of Neurophysiology, vol. 85, no. 6, pp. 2423-2431, 2001.

[18] L. A. Mongiat and A. F. Schinder, "Adult neurogenesis and the plasticity of the dentate gyrus network," European Journal of Neuroscience, vol. 33, no. 6, pp. 1055-1061, 2011.

[19] W. Deng, J. B. Aimone, and F. H. Gage, "New neurons and new memories: how does adult hippocampal neurogenesis affect learning and memory?" Nature Reviews Neuroscience, vol. 11, no. 5, pp. 339-350, 2010.

[20] D.-C. Lie, S. A. Colamarino, H.-J. Song et al., "Wnt signalling regulates adult hippocampal neurogenesis," Nature, vol. 437, no. 7063, pp. 1370-1375, 2005.

[21] M.-H. Jang, M. A. Bonaguidi, Y. Kitabatake et al., "Secreted frizzled-related protein 3 regulates activity-dependent adult hippocampal neurogenesis," Cell Stem Cell, vol. 12, no. 2, pp. 215-223, 2013.

[22] D. R. M. Seib, N. S. Corsini, K. Ellwanger et al., "Loss of dickkopf-1 restores neurogenesis in old age and counteracts cognitive decline," Cell Stem Cell, vol. 12, no. 2, pp. 204-214, 2013.

[23] E. M. Wexler, P. Andres, H. I. Kornblum, T. D. Palmer, and D. H. Geschwind, "Endogenous Wnt signaling maintains neural progenitor cell potency," Stem Cells, vol. 27, no. 10, pp. 1130-1141, 2009.

[24] T. Kuwabara, J. Hsieh, A. Muotri et al., "Wnt-mediated activation of NeuroD1 and retro-elements during adult neurogenesis," Nature Neuroscience, vol. 12, no. 9, pp. 1097-1105, 2009.

[25] Ö. Karalay, K. Doberauer, K. C. Vadodaria et al., "Prosperorelated homeobox 1 gene (Proxl) is regulated by canonical Wnt signaling and has a stage-specific role in adult hippocampal neurogenesis," Proceedings of the National Academy of Sciences of the United States of America, vol. 108, no. 14, pp. 5807-5812, 2011.

[26] A. C. Abbott, C. Calderon Toledo, F. C. Aranguiz, N. C. Inestrosa, and L. Varela-Nallar, "Tetrahydrohyperforin increases adult hippocampal neurogenesis in wild-type and APPswe/PS1 $\triangle \mathrm{E} 9$ Mice," Journal of Alzheimer's Disease, vol. 34, no. 4, pp. 873-885, 2013.

[27] N. C. Inestrosa, C. Tapia-Rojas, T. N. Griffith et al., "Tetrahydrohyperforin prevents cognitive deficit, $\mathrm{A} \beta$ deposition, tau phosphorylation and synaptotoxicity in the APPswe/PSEN1 $\triangle \mathrm{E} 9$ model of Alzheimer's disease: a possible effect on APP processing," Translational Psychiatry, vol. 1, article e20, 2011.

[28] R. Knoth, I. Singec, M. Ditter et al., "Murine features of neurogenesis in the human hippocampus across the lifespan from 0 to 100 years," PLoS ONE, vol. 5, no. 1, Article ID e8809, 2010.

[29] H. G. Kuhn, H. Dickinson-Anson, and F. H. Gage, "Neurogenesis in the dentate gyrus of the adult rat: age-related decrease of neuronal progenitor proliferation," Journal of Neuroscience, vol. 16, no. 6, pp. 2027-2033, 1996.

[30] L. Varela-Nallar, F. C. Aranguiz, A. C. Abbott, P. G. Slater, and N. C. Inestrosa, "Adult hippocampal neurogenesis in aging and Alzheimer's disease," Birth Defects Research C: Embryo Today: Reviews, vol. 90, no. 4, pp. 284-296, 2010.

[31] E. Gould, A. J. Reeves, M. Fallah, P. Tanapat, C. G. Gross, and E. Fuchs, "Hippocampal neurogenesis in adult Old World primates," Proceedings of the National Academy of Sciences of the United States of America, vol. 96, no. 9, pp. 5263-5267, 1999.
[32] J. M. Encinas, A. Vaahtokari, and G. Enikolopov, "Fluoxetine targets early progenitor cells in the adult brain," Proceedings of the National Academy of Sciences of the United States of America, vol. 103, no. 21, pp. 8233-8238, 2006.

[33] G. Kronenberg, K. Reuter, B. Steiner et al., "Subpopulations of proliferating cells of the adult hippocampus respond differently to physiologic neurogenic stimuli," Journal of Comparative Neurology, vol. 467, no. 4, pp. 455-463, 2003.

[34] H. Clevers and R. Nusse, "Wnt/ $\beta$-catenin signaling and disease," Cell, vol. 149, no. 6, pp. 1192-1205, 2012.

[35] Z. Gao, K. Ure, J. L. Ables et al., "Neurod1 is essential for the survival and maturation of adult-born neurons," Nature Neuroscience, vol. 12, no. 9, pp. 1090-1092, 2009.

[36] B. Winner, Z. Kohl, and F. H. Gage, "Neurodegenerative disease and adult neurogenesis," European Journal of Neuroscience, vol. 33, no. 6, pp. 1139-1151, 2011.

[37] D. A. Laplagne, M. S. Espósito, V. C. Piatti et al., "Functional convergence of neurons generated in the developing and adult hippocampus," PLoS Biology, vol. 4, no. 12, article e409, 2006.

[38] H. van Praag, A. F. Schinder, B. R. Christle, N. Toni, T. D. Palmer, and F. H. Gage, "Functional neurogenesis in the adult hippocampus," Nature, vol. 415, no. 6875, pp. 1030-1034, 2002.

[39] E. M. Wexler, D. H. Geschwind, and T. D. Palmer, "Lithium regulates adult hippocampal progenitor development through canonical Wnt pathway activation," Molecular Psychiatry, vol. 13, no. 3, pp. 285-292, 2008.

[40] A. Fiorentini, M. C. Rosi, C. Grossi, I. Luccarini, and F. Casamenti, "Lithium improves hippocampal neurogenesis, neuropathology and cognitive functions in APP mice," PLoS ONE, vol. 5, no. 12, Article ID e14382, 2010.

[41] T.-Y. Eom and R. S. Jope, "Blocked inhibitory serine-phosphorylation of glycogen synthase kinase- $3 \alpha / \beta$ impairs in vivo neural precursor cell proliferation," Biological Psychiatry, vol. 66, no. 5, pp. 494-502, 2009.

[42] M. Sirerol-Piquer, P. Gomez-Ramos, F. Hernández et al., "GSK3beta overexpression induces neuronal death and a depletion of the neurogenic niches in the dentate gyrus," Hippocampus, vol. 21, no. 8, pp. 910-922, 2011.

[43] M. Llorens-Martín, A. Fuster-Matanzo, C. M. Teixeira et al., "GSK-3 $\beta$ overexpression causes reversible alterations on postsynaptic densities and dendritic morphology of hippocampal granule neurons in vivo," Molecular Psychiatry, vol. 18, no. 4, pp. 451-460, 2013.

[44] F. Kayastha, H. Madhu, A. Vasavada, and K. Johar, "Andrographolide reduces proliferation and migration of lens epithelial cells by modulating PI3K/Akt pathway," Experimental Eye Research, vol. 128, pp. 23-26, 2014.

[45] S. Kumar, H. S. Patil, P. Sharma et al., "Andrographolide inhibits osteopontin expression and breast tumor growth through down regulation of PI3 kinase/Akt signaling pathway," Current Molecular Medicine, vol. 12, no. 8, pp. 952-966, 2012.

[46] W.-J. Lu, J.-J. Lee, D.-S. Chou et al., "A novel role of andrographolide, an NF-kappa B inhibitor, on inhibition of platelet activation: the pivotal mechanisms of endothelial nitric oxide synthase/cyclic GMP," Journal of Molecular Medicine, vol. 89, no. 12, pp. 1261-1273, 2011.

[47] D. Widera, I. Mikenberg, M. Elvers, C. Kaltschmidt, and B. Kaltschmidt, "Tumor necrosis factor $\alpha$ triggers proliferation of adult neural stem cells via IKK/NF- $\kappa \mathrm{B}$ signaling," $B M C$ Neuroscience, vol. 7, article 64, 2006. 
[48] S. Denis-Donini, A. Dellarole, P. Crociara et al., "Impaired adult neurogenesis associated with short-term memory defects in NF-kappaB p50-deficient mice," The Journal of Neuroscience, vol. 28, no. 15, pp. 3911-3919, 2008.

[49] L. Varela-Nallar, M. Rojas-Abalos, A. C. Abbott, E. A. Moya, R. Iturriaga, and N. C. Inestrosa, "Chronic hypoxia induces the activation of the Wnt/ $\beta$-catenin signaling pathway and stimulates hippocampal neurogenesis in wild-type and APPswePS1 $\triangle \mathrm{E} 9$ transgenic mice in vivo," Frontiers in Cellular Neuroscience, vol. 8, article 17, 2014.

[50] C. Tapia-Rojas, F. Aranguiz, L. Varela-Nallar, and N. C. Inestrosa, "Voluntary running attenuates memory loss, decreases neuropathological changes and induces neurogenesis in a mouse model of Alzheimer's disease," Brain Pathology, 2015.

[51] H. van Praag, G. Kempermann, and F. H. Gage, "Running increases cell proliferation and neurogenesis in the adult mouse dentate gyrus," Nature Neuroscience, vol. 2, no. 3, pp. 266-270, 1999.

[52] H. van Praag, T. Shubert, C. Zhao, and F. H. Gage, "Exercise enhances learning and hippocampal neurogenesis in aged mice," The Journal of Neuroscience, vol. 25, no. 38, pp. 86808685, 2005. 

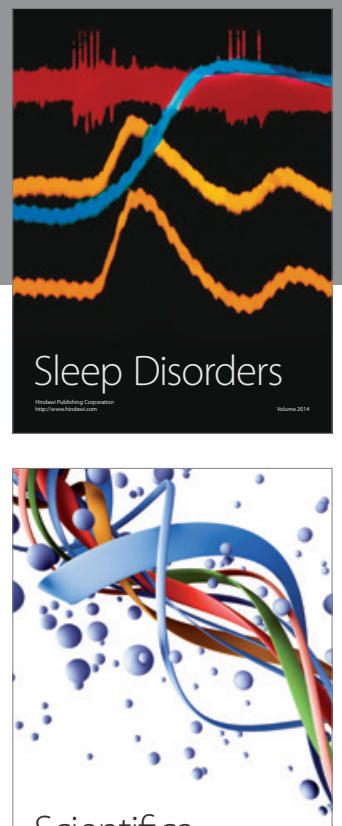

Scientifica
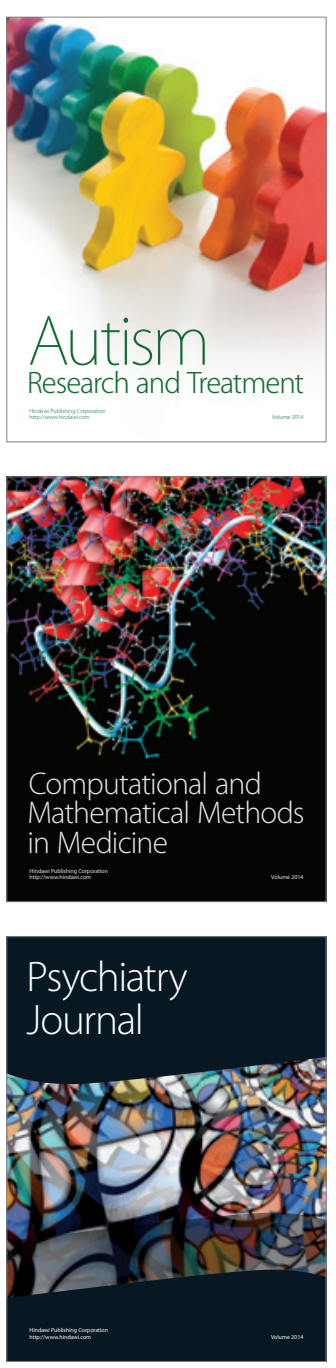
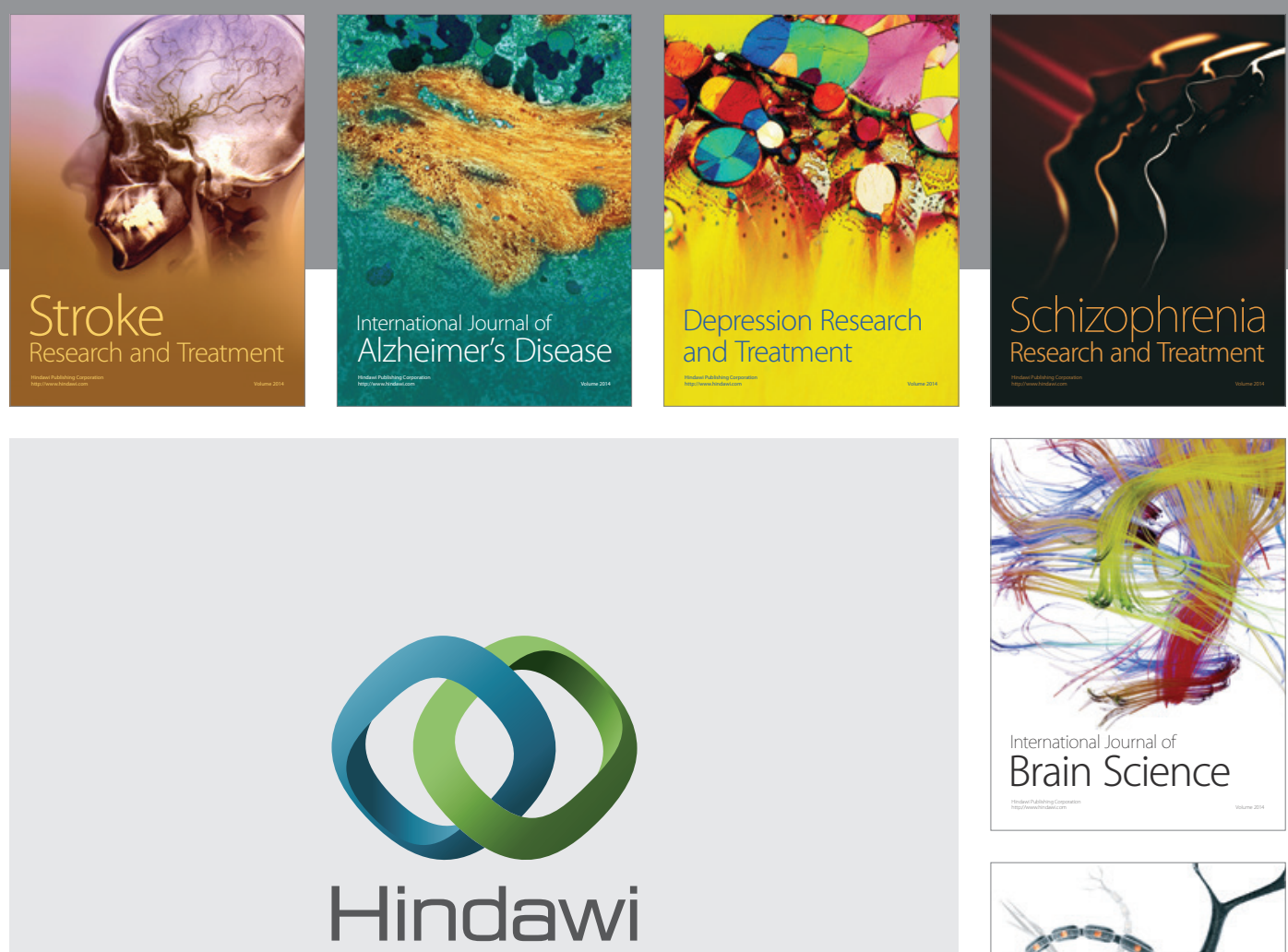

Submit your manuscripts at

http://www.hindawi.com
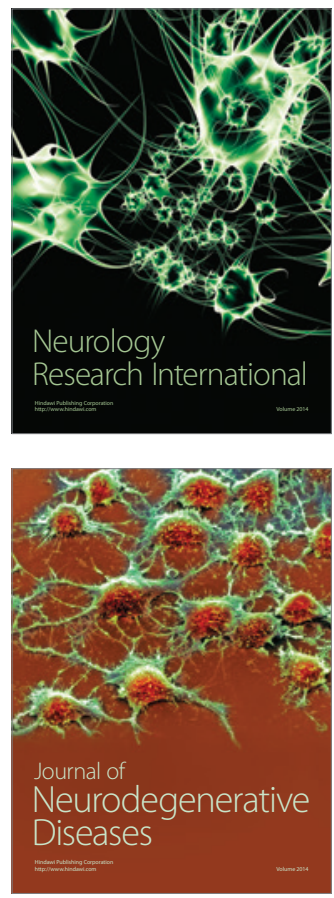

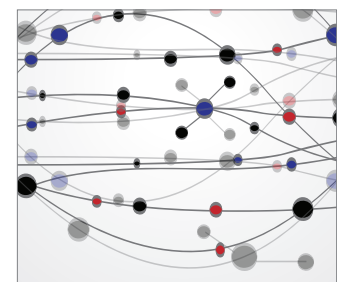

The Scientific World Journal
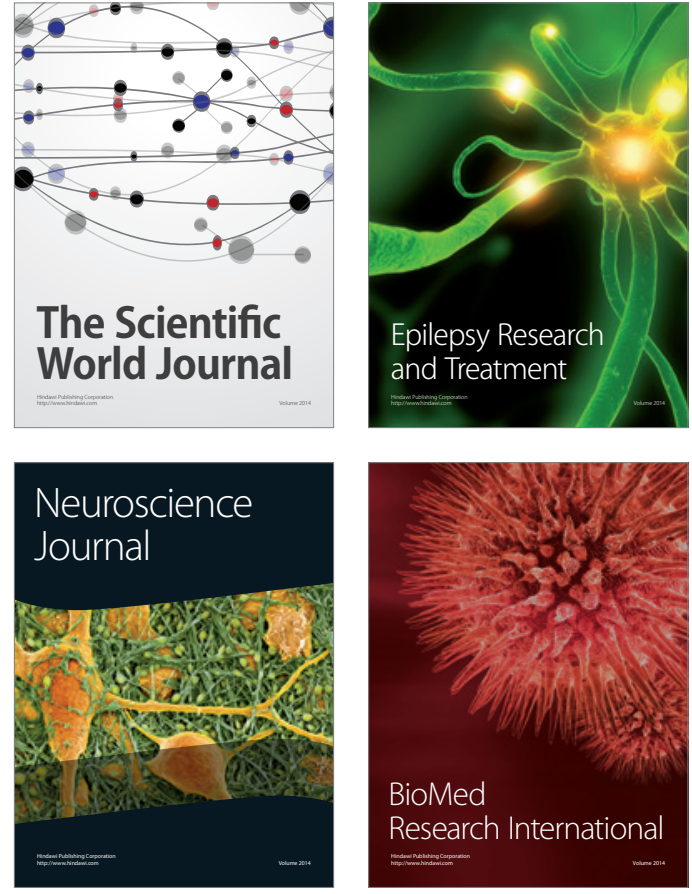

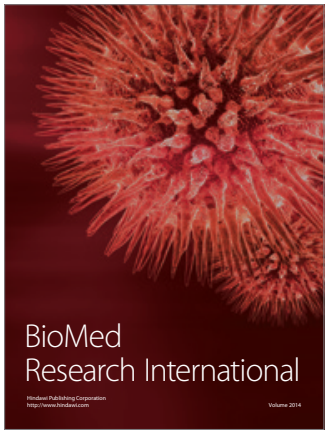

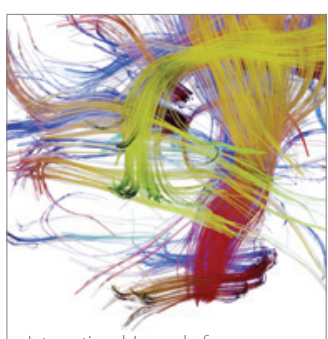

Brain Science

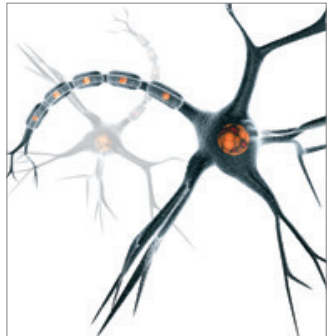

Neural Plasticity
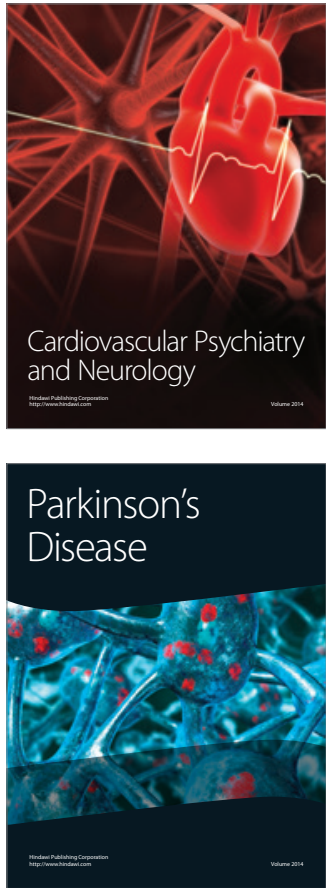